\title{
ISRAELI ARABS DEVELOP DIVERTICULITIS AT A YOUNGER AGE AND ARE MORE LIKELY TO REQUIRE SURGERY THAN JEWS
}

Árabes israelitas desenvolvem diverticulite em idade mais jovem e estão mais sujeitos ao tratamento cirúrgico do que os judeus

Itai GHERSIN ${ }^{1}$, Nadav SLIJPER ${ }^{2}$, Gideon SROKA ${ }^{2}$, Ibrahim MATTER $^{2}$

From the ${ }^{1}$ Rappaport Faculty of Medicine, Technion, Israel Institute of Technology, Haifa, Israel and ${ }^{2}$ Department of Surgery, Bnai Zion Medical Center, Haifa, Israel
ABSTRACT - Background: Only few studies have examined the impact of racial differences on the age of onset, course and outcomes of diverticulitis. Aim: To provide data about the epidemiology of diverticulitis in northern Israel, and to determine whether ethnicity is a predictor of age of onset, complications, and need for surgery. Methods: Was conducted a retrospective review of the charts of all patients diagnosed with a first episode of diverticulitis in our hospital between 2005 and 2012. Results: Were found 638 patients with a first episode of acute diverticulitis in the eight year interval. Israeli Arabs developed a first episode of diverticulitis at a younger age compared to Jews (51.2 vs 63.8 years, $\mathrm{p}<0.01$ ). Arabs living in rural areas developed diverticulitis at a younger age than Arabs living in urban centers (49.4 vs 54.5 years, $P=0.03$ ). Jewish and Arabic men developed diverticulitis at younger age compared to their female counterparts ( 59.9 vs $66.09, p<0.01$, and 47.31 vs 56.93 , $p<0.01$, respectively). Arabs were more likely [odds ratio $(O R)=1.81,95 \%$ confidence interval (CI)1.12-2.90, $p=0.017$ ] than Jews to require surgical treatment (urgent or elective) for diverticulitis. Conclusions: Israeli Arabs tend to develop diverticulitis at a younger age and are more likely to require surgical treatment for diverticulitis compared to Jews. Arabs living in rural areas develop diverticulitis at a younger age than Arabs living in urban centers. These findings highlight a need to address the root cause for ethnic differences in onset, course and outcome of acute diverticulitis.
HEADINGS - Arabs. Colorectal surgery. Diverticulitis. General surgery. Jews. Israel.
RESUMO - Racional: Somente poucos estudos examinaram o impacto das diferenças raciais na idade de início, curso e os resultados da diverticulite. Objetivo: Fornecer dados sobre a epidemiologia da diverticulite no norte de Israel, e determinar se a etnia é preditor de idade de início, complicações e necessidade de tratamento cirúrgico. Métodos: Foi realizado estudo retrospectivo dos prontuários de todos os pacientes diagnosticados com um primeiro episódio de diverticulite em nosso hospital entre 2005 e 2012. Resultados: Foram encontrados 638 pacientes com um primeiro episódio de diverticulite aguda no intervalo de oito anos. Os árabes israelenses desenvolveram o primeiro episódio de diverticulite em idade mais jovem em comparação com os judeus ( 51,2 vs 63,8 anos, $p<0,01$ ). Árabes que vivem em áreas rurais a diverticulite foi desenvolvida em idade mais jovem do que os árabes que vivem em centros urbanos $(49,4$ vs 54,5 anos, $p=0,03)$. Homens judeus e árabes desenvolveram diverticulite em idade mais jovem em comparação com os seus homólogos do sexo feminino $(59,9$ vs $66,09, p<0,01$, e 47,31 vs $56,93, p<0,01$, respectivamente). Os árabes eram mais prováveis do que os judeus de necessitar de tratamento cirúrgico (urgência ou eletiva) para a diverticulite [odds ratio $(O R)=1,81$, intervalo de confiança de $95 \%$ (CI) $1,12-2,90, p=0,017$ ] Conclusões: Os árabes israelenses tendem a desenvolver diverticulite em idade mais jovem e são mais propensos a necessitar de tratamento cirúrgico para a diverticulite em comparação com os judeus. Árabes que vivem em áreas rurais desenvolvem diverticulite em idade mais jovem do que os árabes que vivem em centros urbanos. Estes resultados destacam a necessidade de abordar a causa raiz para diferenças étnicas em início, o curso e o resultado da diverticulite aguda.
DESCRITORES - Árabes. Cirurgia colorretal. Diverticulite. Cirurgia geral. Judeus. Israel.

\section{INTRODUCTION}

$\mathrm{D}$ iverticular disease of the colon is a common disease with increasing prevalence in Western countries. The incidence of diverticular disease rises with age, and by the age of 85 about $65 \%$ of the population is expected to be affected ${ }^{21}$. It is less frequent in the younger age group, but the incidence of diverticulitis in younger patients appears to be on the rise ${ }^{10,22}$. Most patients with diverticulosis will remain asymptomatic, and only $10-25 \%$ will go on to develop diverticulitis ${ }^{21}$. The clinical presentation of acute diverticulitis can vary widely, from mild inflammation to colonic perforation and peritonitis, yet most cases are mild and respond to antibiotic therapy.

The impact of ethnicity on the course and outcome of diverticulitis has not been studied extensively. Few studies addressing this issue have been recently performed in the United States, revealing that African American patients with diverticulitis are more likely to require urgent/emergent surgery $\mathrm{y}^{1,20}$ and surgery for recurrent disease $\mathrm{e}^{5}$, and are at increased risk for disease recurrence, morbidity and mortality ${ }^{1,16,20}$. Data 
regarding the epidemiology of diverticular disease in Israel is scarce and outdated, and the impact of ethnicity on disease course and outcome in Israeli patients has not been investigated.

There is conflicting data regarding the course and outcome of diverticulitis in young patients. While some studies reported a more severe course with a higher rate of complications in young patients with diverticulitis ${ }^{3,13}$, other reports suggested a milder course, comparable to that in older patients ${ }^{12,26}$

The aim of this study was to performed a retrospective analysis of all patients hospitalized in our hospital with a first episode of acute diverticulitis during an 8-year period, and compared the course and outcome of diverticulitis in Arab patients to that of Jewish patients, and also make a similar comparison between younger and older patients.

\section{METHODS}

This study was carried out in accordance with the ethical standards laid down in the 1975 Declaration of Helsinki and its later amendments.

\section{Patients}

All patients hospitalized at our medical center with a first episode of acute diverticulitis between January 2005 to December 2012 were enrolled. Our patients' population included all patients diagnosed with acute diverticulitis in the emergency room, as our institution's policy is to hospitalize all patients with acute diverticulitis, regardless of disease severity.

\section{Methods}

The diagnosis of acute diverticulitis was based on typical clinical features, including lower abdominal pain (mostly left-sided), fever and leukocytosis. All patients underwent abdominal $\mathrm{CT}$, and only those with characteristic findings on CT were included. Patients with a lesion suspicious of colonic cancer and patients with right-sided diverticulitis on CT scan were excluded. Patients with previous episodes of acute diverticulitis were excluded as well. Demographic characteristics, medical history, physical and radiographic findings as well as therapy were recorded.

Data was analyzed for the whole group, and then for subgroups according to ethnicity (Jewish vs. Arab) and age $(<50 \mathrm{yr},>50 \mathrm{yr}$ ). The age of 50 years was chosen, as it was used in several previous studies addressing diverticulitis in young patients ${ }^{3,26}$.

\section{Statistical analysis}

Began with descriptive statistics: means, standard deviations and ranges for diagnostic and outcome measures, then student's T-test and Fisher exact test were used to compare between the groups. Statistical significance was set as $p<0.05$.

\section{RESULTS}

A total of 638 patients were hospitalized with a first episode of diverticulitis between January 2005 and December 2012. Of this total, 538 (84.3\%) were Jews and 100 (15.7\%) were Arabs; 253 were males and 385 females.

When analyzing patient age at first episode of acute diverticulitis (Table 1 ) was noted that Israeli Arabs developed a first episode of diverticulitis at a significantly younger age compared to Jews (51.2 vs 63.8 years, $p<0.001$ ). Both Jewish and Arab men developed diverticulitis at a younger age compared to their female counterparts (Table 1 ).
TABLE 1 - Age (average \pm standard deviation) at first acute diverticulitis episode

\begin{tabular}{c|c|c|c|c|}
\hline & & Jews & Arabs & $\mathrm{p}$ \\
\hline Male & Age $(n)$ & $59.90 \pm 15.15(194)$ & $47.31 \pm 13.10(59)$ & $<0.01$ \\
\hline Female & Age $(n)$ & $66.09 \pm 13.30(344)$ & $56.93 \pm 12.37(41)$ & $<0.01$ \\
\hline & $P$ & $<0.01$ & $<0.01$ \\
Total & Age (n) & $63.86 \pm 14.29(538)$ & $51.25 \pm 12.37(100)$ & $<0.01$ \\
\hline
\end{tabular}

Arabs living in rural areas developed diverticulitis at a younger age than Arabs living in urban centers (49.4 vs 54.5 years, $p=0.03$ ).

Therewasnosignificant difference between ethnicgroups [odds ratio $(O R)=1.10,95 \%$ confidence interval $(C I)=0.48$ $2.52, P=1$ ] in the odds of requiring an acute intervention (urgent surgery or CT-guided percutaneous drainage) during their initial hospitalization with acute diverticulitis (Table 2). However, Arabs were significantly more likely [odds ratio $(\mathrm{OR})=1.81,95 \%$ confidence interval $(\mathrm{CI}) 1.12-2.90, \mathrm{P}=0.017]$ than Jews to undergo surgical treatment at any stage (either urgent or elective) for diverticular disease (Table 3).

TABLE 2 - Need for acute intervention in first acute diverticulitis episode

\begin{tabular}{|c|c|c|}
\hline & Jews & Arabs \\
\hline Acute Interventiont & 41 & 7 \\
\hline Conservative Treatment & 497 & 93 \\
\hline$p=1$ & & \\
\hline
\end{tabular}

†Acute intervention - urgent surgery or CT-guided percutaneous drainage during initial hospitalization

TABLE 3 - Eventual need for surgical treatment for diverticular disease

\begin{tabular}{|c|c|c|}
\hline & Jews & Arabs \\
\hline Surgery ${ }^{+}$ & 107 & 31 \\
\hline No Surgery & 431 & 69 \\
\hline$p=0.017$ & & \\
\hline
\end{tabular}

+Both urgent and elective surgeries

There was no difference in outcome when comparing younger (age $<50$ years) with older patients (age $>50$ years).

\section{DISCUSSION}

This study addresses the impact of race/ethnicity and age on the course and outcome of diverticulitis among Israeli patients. Was found that Israeli Arabs tend to develop diverticulitis at a younger age and are more likely to require surgical treatment for diverticulitis compared to Jews. Arabs living in rural areas develop diverticulitis at a younger age than Arabs living in urban centers.

Only few studies have examined the impact of race/ethnicity on presentation, course and outcome of diverticulitis. Most of these studies were conducted in the United States. It was suggested that African American patients are more likely than Caucasians to require emergent/urgent surgical treatment $\mathrm{t}^{1,20}$ and surgical treatment for recurrent diverticulitis ${ }^{5}$. Risk for morbidity and mortality was also increased among African Americans ${ }^{1,16,20}$. Some studies have suggested that insurance status, rather than race, is a risk factor for mortality in acute diverticulitis ${ }^{11}$. However, a study comparing diverticulitis in African American and Caucasian Medicare patients revealed that African Americans were still at a higher risk for requiring urgent/emergent operation and mortality, thus suggesting that factors other than insurance status play a role in the worse outcomes observed in African American patients ${ }^{20}$.

Israel has a social, government owned, health care 
system, hence differences in insurance status between patients are minor/non-relevant. As a result we do not believe that insurance or socioeconomic status plays a major role in explaining our findings.

Very few data exists regarding the epidemiology of diverticulitis in Israel. Levy et al. studied the epidemiology of diverticulosis in Northern Israel in two consecutive studies, the first conducted in the early 1970 ' $\mathrm{s}^{14}$ and the second a decade later ${ }^{15}$. They found a three-fold increase in the prevalence of diverticulosis among Sephardi Jews and a seven-fold increase in the prevalence of diverticulosis in Arab patients, while disease prevalence among Ashkenazi Jews remained stable during that 10 year period. These articles, however, studied the epidemiology of diverticulosis and not of diverticulitis, and were performed several decades ago, with no data regarding disease epidemiology among the different ethnic groups published in recent decades.

It is interesting to note that Arab patients comprised only $15.7 \%$ of this patient group. Our medical center mainly serves Israel's Haifa District and Northern District, which according to the Israeli Central Bureau of Statistics data for 2011 had Arabs making up 25.1\% and 53.2\% of their populations, respectively. While apparently having less of a risk of developing diverticulitis based on these data, those Arab patients who do develop diverticulitis have a significantly more severe disease course, as shown above.

Our findings regarding the impact of place of residence on the development of diverticulitis were somewhat surprising. Burkitt's "fiber hypothesis", suggesting that a lack of dietary fiber predisposes individuals to diverticular disease ${ }^{6,7,18}$, has long been accepted in explaining the pathogenesis of diverticular disease. Rural population in general, and the rural Arab population in particular, is generally thought to consume higher amounts of dietary fiber than urban population. However, in this study the subgroup of rural Arab patients developed diverticulitis at a significantly younger age than their urban Arab counterparts. This might suggest that factors other than dietary fiber could also play a role in the development of diverticular disease.

There is conflicting evidence regarding the natural course of diverticulitis in young patients. Some studies have reported that young patients have a more severe course with a higher complication rate, thus suggesting that an earlier surgical approach should be considered in young patients with acute diverticulitis $23,8,9,13,17,19$.

Others, however, found that the course of diverticulitis in young patients is not different from that in the general population, hence suggesting young patients should be managed in a similar fashion to older ones ${ }^{4,10,12,22,23,24,26}$. This study also failed to demonstrate a difference in disease course, complication rate and outcome between younger and older patients. Further research is needed in order to clarify this matter of debate. It is worth noting that a male predominance was seen in our young patient group, a pattern also noted in past studies ${ }^{4,12,13}$.

This study has several limitations. First, it is a retrospective study, and prospective studies regarding the impact of epidemiological factors on the course and outcome of diverticulitis are needed, in order to further investigate the matter and confirm our findings. In addition, the study is a single-center study, and thus our group of patients may not be fully representative of the entire Northern Israeli population, which is served by several medical centers, let alone the whole state of Israel. Larger scale studies, perhaps even on a national scale, could lead to more robust and comprehensive evidence.

\section{CONCLUSION}

We were able to demonstrate that Israeli Arabs are more likely to develop diverticulitis at a younger age and to require surgical treatment for diverticulitis compared to Jews. Future research should focus on identifying the root causes for these differences. Our data presents a rationale for very careful follow-up of Israeli Arab patients following medical treatment for diverticulitis.

\section{REFERENCES}

1. Alavi K, Cervera-Servin JA, Sturrock PR, Sweeney WB, Maykel JA. Racial differences in short-term surgical outcomes following surgery for diverticulitis. J Gastrointest Surg. 2012 Mar;16(3):613-21

2. Ambrosetti $P$, Gervaz $P$, Fossung-Wiblishauser A. Sigmoid diverticulitis in 2011: many questions; few answers. Colorectal Dis. 2012 Aug;14(8):e439-46.

3. Ambrosetti P, Robert JH, Witzig JA, Mirescu D, Mathey P, Borst F, Rohner A. Acute left colonic diverticulitis in young patients. J Am Coll Surg. 1994 Aug;179(2):156-60.

4. Biondo S, Parés D, Martí Ragué J, Kreisler E, Fraccalvieri D, Jaurrieta E. Acute colonic diverticulitis in patients under 50 years of age. $\mathrm{Br} J$ Surg. 2002 Sep;89(9):1137-41.

5. Bose KP, Khorshidi I, Southern WN, Brandt LJ. The impact of ethnicity and obesity on the course of colonic diverticulitis. J Clin Gastroenterol. 2013 Feb;47(2):160-4.

6. Burkitt DP, Walker AR, Painter NS. Dietary fiber and disease. JAMA. 1974 Aug 19;229(8):1068-74

7. Burkitt DP.Epidemiology of large bowel disease: the role of fibre. Proc Nutr Soc. 1973 Dec;32(3):145-9.

8. Chautems RC, Ambrosetti P, Ludwig A, Mermillod B, Morel P, Soravia C. Long-term follow-up after first acute episode of sigmoid diverticulitis: is surgery mandatory?: a prospective study of 118 patients.Dis Colon Rectum. 2002 Jul;45(7):962-6.

9. Freischlag J, Bennion RS, Thompson JE Jr. Complications of diverticular disease of the colon in young people. Dis Colon Rectum. 1986 Oct;29(10):639-43.

10. Guzzo J, Hyman N. Diverticulitis in young patients: is resection after a single attack always warranted? Dis Colon Rectum. 2004 Jul;47(7):118790; discussion 1190-1.

11. Ho VP, Nash GM, FeldmanEN, Trencheva K, MilsomJW, Lee SW. Insurance but not race is associated with diverticulitis mortality in a statewide database. Dis Colon Rectum. 2011 May;54(5):559-65

12. Kaiser AM, Jiang JK, Lake JP, Ault G, Artinyan A, Gonzalez-Ruiz C, Essani R, Beart RW Jr. The management of complicated diverticulitis and the role of computed tomography. Am J Gastroenterol. 2005 Apr;100(4):910-7.

13. Lahat A, Menachem Y, Avidan B, Yanai H, Sakhnini E, Bardan E, Bar-Meir S. Diverticulitis in the young patient--is it different? World J Gastroenterol. 2006 May 14;12(18):2932-5.

14. Levy N, Luboshitzki R, ShiratzkiY, Ghivarello M. Diverticulosis of the colon in Israel. Dis Colon Rectum. 1977 Sep;20(6):477-81.

15. Levy N, Stermer E, Simon J. The changing epidemiology of diverticular disease in Israel. Dis Colon Rectum. 1985 Jun;28(6):416-8.

16. Lidor AO, Gearhart SL, Wu AW, Chang DC. Effect of race and insurance status on presentation, treatment, and mortality in patients undergoing surgery for diverticulitis. Arch Surg. 2008 Dec;143(12):1160-5;

17. Minardi AJ Jr, Johnson LW, Sehon JK, Zibari GB, McDonald JC. Diverticulitis in the young patient. Am Surg. 2001 May;67(5):458-61.

18. Painter NS, Burkitt DP. Diverticular disease of the colon: a deficiency disease of Western civilization. Br Med J. 1971 May 22;2(5759):450-4.

19. Schauer PR, Ramos R, Ghiatas AA, Sirinek KR. Virulent diverticular disease in young obese men. Am J Surg. 1992 Nov;164(5):443-6; discussion 446-8

20. Schneider EB1, Haider A, Sheer AJ, Hambridge HL, Chang DC, Segal JB, Wu AW, Lidor AO. Differential association of race with treatment and outcomes in Medicare patients undergoing diverticulitis surgery Arch Surg. 2011 Nov;146(11):1272-6

21. Schoetz DJ Jr. Diverticular disease of the colon: a century-old problem. Dis Colon Rectum. 1999 Jun;42(6):703-9.

22. Schweitzer J, Casillas RA, Collins JC. Acute diverticulitis in the young adult is not "virulent.". Am Surg. 2002 Dec;68(12):1044-7.

23. Spivak H, Weinrauch S, Harvey JC, Surick B, Ferstenberg $H$, Friedman I. Acute colonic diverticulitis in the young. Dis Colon Rectum. 1997 May;40(5):570-4

24. Vignati PV, Welch JP, Cohen JL. Long-term management of diverticulitis in young patients. Dis Colon Rectum. 1995 Jun;38(6):627-9.

25. Welch CA, Allen AW, Donaldson GA. An appraisal of resection of the colon for diverticulitis of the sigmoid. Ann Surg. 1953 Sep;138(3):332-43..

26. West SD, Robinson EK, Delu AN, Ligon RE, Kao LS, Mercer DW. Diverticulitis in the younger patient. Am J Surg. 2003 Dec;186(6):743-6. 